\title{
Los estudios judaicos desde Cuba, 1986-2014 ${ }^{1}$ \\ Jewish studies in Cuba, 198-2014
}

Maritza Corrales Capestany

emc2@cubarte.cult.cu

Universidad de la Habana

Cuba

\section{Resumen}

En el siguiente trabajo se describe cómo se han desarrollado los estudios judaicos en Cuba desde fines del siglo XIX hasta principios del XXI. Para ello, se analiza la formación de la comunidad judía en Cuba y, sobre todo, los distintos estudios académicos que se han elaborado en torno al judaísmo en dicho país.

Palabras claves: Cuba, judaísmo, estudios judaicos, comunidad judía.

\begin{abstract}
The following work describes how Jewish studies in Cuba have developed since the late nineteenth century until the beginning of the twenty-first century. The author analyze the formation of the Jewish community in Cuba and, above all, the different academic studies that have been developed around Judaism in that country.
\end{abstract}

Key words: Cuba, Judaism, Jewish studies, Jewish community.

\section{Introducción}

Alejo Carpentier, interrogado sobre el origen de los cubanos y su procedencia geográfica, con una síntesis que contradecía su desbordante prosa barroca, respondió sólo tres palabras: "de los barcos."

${ }^{1}$ Ponencia presentada en la XVIII Conferencia de LAJSA, Miami 2015.

Cuadernos Judaicos ISSN: 0718-8749 
Cuba es un incuestionable "pueblo nuevo" surgido de la transculturación de matrices indígenas, negras y europeas, integradas y fusionadas para crear esa cultura mestiza y sincrética que Don Fernando Ortiz diera en llamar el ajiaco cubano. Popular, heterodoxo y democrático símbolo de nuestra cocina donde cada elemento que se añade se integra en el aroma resultante, sin que ello implique la pérdida de su sabor original.

El núcleo inicial del etnos cubano, conformado por una muy diezmada población indígena, los conquistadores españoles y una numerosa diáspora africana, cuya esclavitud se extendió junto con la de Brasil mucho más allá que las del resto del continente, se vio enriquecido en los siglos XIX y XX por dos oleadas inmigratorias cuantitativamente importantes: la china a partir de 1847 y la española en los albores de la República, después que la Metrópoli perdiera la "Siempre Fiel Isla de Cuba".

En el lapso de apenas una generación nuestro monto demográfico se incrementó en un millón doscientos ochenta mil habitantes, ubicándonos como un país de inmigración al mismo nivel, proporcionalmente hablando, de Australia, Estados Unidos o las naciones del Plata. $^{2}$

Hasta ese momento, en nuestra historia, "la cultura judía había solido estar escondidiza entre la de otros grupos...nos llegó con los españoles de todas las regiones...se infiltró...so capa de portugueses, de flamencos, de italianos, de británicos, de franceses, hasta de alemanes y luego de norteamericanos y polacos". ${ }^{3}$

No será hasta el siglo XX, tras el fin de la Guerra con España en 1898 con la llegada de grupos norteamericanos relacionados con el proceso inversionista de ese país en Cuba, que aquella escondidiza cultura comience a hacerse visible. Luego, la Revolución de los Jóvenes Turcos en 1908, las Guerras Balcánicas de 1912 y la Primera Guerra Mundial, pero

\footnotetext{
${ }^{2}$ Juan Pérez de la Riva, Los recursos humanos de Cuba al comenzar el siglo: Inmigración, economía y nacionalidad, p.11.

${ }^{3}$ Fernando Ortiz, Los factores humanos de la cubanidad, p.85.
} 
sobre todo las Leyes de Cuota norteamericanas de 1921 y 1924, propiciarían la conformación de una multifacética comunidad que se desarrolló, ininterrumpidamente, hasta su casi virtual extinción en la década de los setenta del pasado siglo.

En el periodo que analizaremos, de 1986 al 2014, la pequeña comunidad judía cubana -que sobrevivió al impacto de la Revolución de 1959- osciló entre 600 y 1500 miembros, en su mayoría conversos, dentro de un estado que desde 1973 había cortado sus vínculos diplomáticos con Israel, por lo que sería lógico presumir cierta precariedad del tema en nuestro mundo académico.

Sin embargo, los datos resultan sorprendentes. El número de tesis realizadas, directa o tangencialmente, sobre esta temática en Cuba supera ampliamente las dedicadas a las restantes minorías que nos habitan, ${ }^{4}$ tanto desde el punto de vista histórico como político o religioso, a pesar de no existir como en otros países del área un proceso de institucionalización de los estudios judaicos, ni un campo académico donde se construya dicho objeto de estudio y se dialogue transdisciplinariamente sobre el mismo.

Nuestro trabajo, basado en una muestra de 78 tesis de grado, maestría y doctorado de las carreras de Ciencias Sociales y Humanidades, elaboradas en la Universidad de La Habana y en los centros de enseñanza superior e investigación que le están subordinados, incluyendo los religiosos $^{5}$, sopesa la presencia de esta temática en sus agendas investigativas

\footnotetext{
${ }^{4}$ Llama la atención que en la búsqueda realizada aparezcan seis tesis sobre la comunidad hebrea cubana, pero que no se aborden académicamente asentamientos comunitarios de grupos migratorios de mayor peso demográfico en el país, si exceptuamos un trabajo elaborado sobre el barrio chino de La Habana.

De igual forma, aunque las investigaciones sobre los árabes casi alcancen en número a la de los judíos, estas solo valoran el rol que el bloque árabe desempeña en política internacional obviando su presencia dentro de la sociedad cubana, en tanto que la de chinos y japoneses se refieren fundamentalmente a aspectos del intercambio económico con la isla o a la importancia políticoregional que esos países detentan en su área específica.

5 El número sabemos es muy superior pero, desafortunadamente, algunos de los centros de investigación donde se produjeron tesis han cesado sus funciones con la consecuente disolución de sus archivos. Asimismo, la exigencia de entregarlas a la biblioteca de cada Facultad tras los ejercicios de defensa no siempre se cumple y, en ocasiones, se toman prestadas y no son devueltas por lo que su inclusión, aunque recordemos su existencia, es imposible.
} 
destacando las causas que provocaron el énfasis o la carencia de determinadas aristas en dichos estudios.

\section{Cuba y lo judío}

En Cuba existen definiciones identitarias que por un lado nos acercan a valoraciones sobre la historia, la cultura y la religión judía, sin duda empáticas, mientras que por otro en ocasiones nos extrañan e inclinan a controversiales interpretaciones políticas.

Aun cuando tradicionalmente se nos clasifique como una nación católica, dada la antigua data de esta religión en la isla y la lógica asunción de que como buena parte de los latinoamericanos debemos profesar dicha creencia, esta definición en puridad resulta más nominal que real.

La conflictiva historia institucional de esta Iglesia con el entorno nacional, y la evidente permeabilidad de cada esfera de nuestra sociedad por aquellas manifestaciones de religiosidad popular, espíritas y de origen africano, no sólo nos distancian de esa estricta clasificación confesional sino, también, de aquellas variables de percepción sobre lo judío que han acompañado al catolicismo más militante en ciertos momentos de su devenir histórico, confiriéndonos la posibilidad de acercamientos totalmente asépticos a la religión, al pensamiento y a la cultura de este pueblo sin trazas de discriminación, antisemitismo o xenofobia.

A estos señalamientos sobre la tradicional parquedad católica del cubano y la erosión que dicha institución sufriera, tras los diferendos Estado-Iglesia de los años iniciales, podría añadirse la traspolación, posible y probable, de aspectos medulares del pensamiento y la religión judía a la Cuba de hoy realizada por aquellos sectores del protestantismo que, con la conformación de una "nueva teología", obtuvieron rotunda voz y presencia a lo largo del periodo revolucionario. 
De igual modo, las posiciones antiimperialistas y tercermundistas cubanas junto al comprometimiento político con estos países en la esfera internacional, llevó a la isla a identificarse con el movimiento de liberación palestino y con todas aquellas naciones que como Iraq, Irán o Libia se enfrentaran ideológicamente a las acciones regionales o globales norteamericanas.

De ahí que asumamos la inusitada y decidida presencia del tema judío en la agenda investigativa nacional, y las peculiaridades de su tratamiento, como condicionadas por la conjunción de tres factores que, a su vez, determinarían las principales vertientes de análisis:

- El auto reconocimiento del país como integrante del bloque socialista y también del de los no-alineados lo que, junto a la agudización del omnipresente y ancestral diferendo con los Estados Unidos, estructuró una forma de definición ideológica de la Revolución cubana que ha atravesado y, aún atraviesa, buena parte del pensamiento de las Ciencias Sociales y Políticas en la isla.

- El accionar de una diferente "teología de la liberación" estructurada, hacia lo interno de la nación, por las denominaciones protestantes actuantes en el país.

- El interés despertado en el medio académico, en la década de los 90, por conferencias y publicaciones sobre el tema, la revitalización de la comunidad judía y la introspección existencial del cubano tras la crisis del "socialismo real" en la Europa Oriental.

Dados estos presupuestos, y en función de una mejor aprehensión del fenómeno en su integralidad, establecimos tres categorías de clasificación para la selección de los trabajos que incluyeran, con una mirada cruzada y una perspectiva diacrónica, la intersección de lo judío con lo cubano, con el judaísmo -no sólo como religión sino también como pensamiento filosófico-, y con la realidad política generada por el estado de Israel. 
La primera selección recopila y grafica, analizando sus posibles causales y agrupándolos por nivel de complejidad académica, aquellos trabajos realizados en las décadas ${ }^{6}$ de $\operatorname{los}$ ochenta, los noventa y del dos mil, que se corresponden con los tres aspectos o subtemas de los estudios judaicos más frecuentados entre nosotros: el comportamiento político israelí/norteamericano, la religión y el pensamiento judíos, y el acontecer histórico y los valores patrimoniales de su comunidad nacional.

La segunda profundiza el análisis, con una visión más focalizada, de las causas internas y externas de mayor incidencia en la producción académica en los periodos comprendidos entre 1986- 1999 y 2000-2014.

La tercera valora el papel de las diferentes facultades universitarias y centros de investigación, en relación con los tres subtemas identificados.

\section{Tesis por décadas y temáticas}

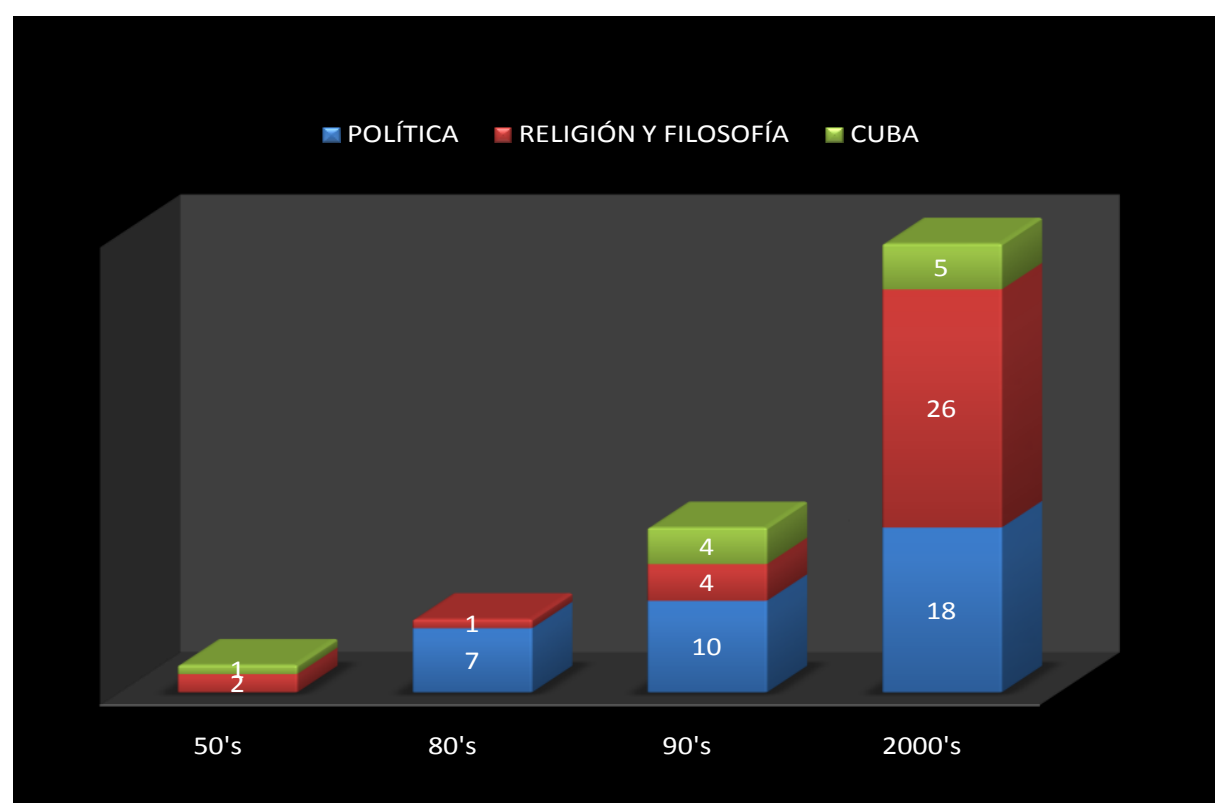

\footnotetext{
${ }^{6}$ Décadas que no son estrictamente de diez años cada una, ya que tomamos como punto de partida 1986, fecha en que aparece la primera tesis, y concluimos en el 2014.
} 
A modo de antecedente, en la década de los '50, encontramos tres tesis, centradas sólo en las facetas comunitarias e histórico-religiosas de este grupo migratorio. ${ }^{7}$

Al comparar este dato con el desarrollo ulterior experimentado por dicho objeto de estudio en el país y las líneas de investigación privilegiadas a partir de 1986 constatamos, como rasgos distintivos, la total ausencia en dicho periodo del análisis político que caracterizará los trabajos de décadas posteriores, y la escasa participación de miembros de la comunidad en la elaboración de trabajos académicos, ${ }^{8}$ a pesar de contar entonces la kehillá con 15000 afiliados, ampliamente representados en las aulas universitarias.

Hay un grupo de publicaciones, no incluidas en la cuantificación por ser trabajos producidos en un medio no académico, que queremos reseñar dado el peso cultural que tuvieron y que expresan el interés ${ }^{9}$ de esa comunidad de interrelacionarse con la sociedad receptora. Las series ${ }^{10}$ promovidas por la Agrupación Cultural Hebreo-Cubana, con motivo del Centenario del nacimiento de José Martí (1953) y la inauguración de la Casa de la Comunidad Hebrea de Cuba (1955), sin dudas impactaron la opinión pública y confirieron carta de naturalización a este grupo migratorio, a juzgar por la profusión de artículos y críticas reflejadas en la prensa nacional que destacan esa nueva identidad judío-cubana, ya en franca cristalización.

Otros folletos, elaborados también por las estructuras comunitarias, destacan el pensamiento de figuras como Teodoro Herzl, Albert Einstein, la obra literaria de escritores

\footnotetext{
${ }^{7}$ Una sobre el trabajo asistencial de los hebreos en Cuba, y dos del Seminario Teológico de Matanzas (SET) analizando las sectas del judaísmo existentes en la época de Jesús.

${ }^{8}$ Sólo una, la del trabajo asistencial de los hebreos en Cuba ya mencionada.

${ }^{9}$ Interés que produjo el primer libro sobre la comunidad hebrea cubana, The Jewish Community of Cuba. Settlement and Growth, realizado por Boris Sapir durante su estancia como refugiado en La Habana y que fuera publicado con posterioridad, en 1948, en los Estados Unidos.

${ }^{10}$ Un total de 8 libros y folletos de ensayo y poesía con los más diversos acercamientos a la figura de nuestro héroe nacional y a símbolos patrios como la bandera cubana. Estas publicaciones y el libro Martí y la comprensión humana, constituyen uno de los homenajes más originales y sentidos al hacedor de nuestra independencia que jamás haya realizado una comunidad de inmigrantes radicada en el país. Ver estudio De libertades y exilios: José Martí y los hebreos cubanos, AMILAT, Universidad Hebrea de Jerusalem, 2009.
} 
como Yehuda Haleví, Rodrigo Cota y Najman Bialik, la vida judía en el país con la Síntesis histórica de los hebreos de Cuba de Dionisio Castiel, o diversos aspectos de la sociedad israelí referidos al funcionamiento de la Universidad Hebrea de Jerusalén o la ciencia en Israel y América Latina.

En la década de los '80 hay dos momentos históricos, en los que convendría profundizar ya que cruzan y marcan, en mayor o menor grado, la producción de buena parte de los trabajos reseñados de 1986 a la actualidad.

La entrada de Cuba al CAME en 1972, con la subsecuente profundización de nuestras relaciones con el campo socialista y la aceptación de la estrategia geopolítica de la URSS en el área, implicó a lo interno un aumento de la asesoría soviética y de Alemania oriental en la educación del país. Asesoría que traspoló, esquemáticamente, a las escuelas cubanas el modelo soviético de enseñanza de la historia, limitando el campo visual y metodológico de las Ciencias Sociales a un enfoque plausible pero, aún así, incompleto. ${ }^{11}$ Mientras que a lo externo estructuró una percepción, en cierto modo sesgada, de la muy compleja y multifactorial problemática medioriental.

El derrumbe de las estructuras del socialismo en 1989 y nuestro prolongado "periodo especial" provocó no sólo un incremento de las religiones en el país, sino también una nueva reflexión de la historia nacional y un alejamiento relativo del peso europeo en la enseñanza de esta materia, que abrió espacios analíticos de mayor alcance para la comprensión del devenir histórico mundial. ${ }^{12}$

\footnotetext{
${ }^{11}$ Este modelo privilegió una historia eurocentrista y fragmentada, que otorgó mayor relevancia a aspectos políticos y económicos europeos, en especial del movimiento comunista desde la Revolución de Octubre hasta los años setenta, en detrimento de la historia de América Latina, Asia o África. Asimismo, los libros que circulaban e influenciaban esta enseñanza en gran parte provenían del campo socialista. Ver tesis inédita de Mileidys Pérez, "La enseñanza de la historia de Cuba a nivel secundario desde el triunfo de la Revolución hasta 1988", Universidad de La Habana, 2001.

${ }^{12}$ Los programas de Historia de Cuba que se imparten en tercer año abordan la dinámica de los movimientos obrero y comunista, entre 1920 y 1925, y el ascenso del movimiento popular revolucionario cubano de los años 30, en los que la participación judía superó ampliamente la de otros grupos étnicos de mayor peso demográfico en la isla, como chinos y españoles, pero no 
El número de tesis producidas en esta década, todas de grado, se incrementa a ocho. Siete motivadas por dos eventos políticos claves, la primera Intifada y la aceptación de la OLP y de Estados Unidos de iniciar contactos. De ellas, dos se enfocan al sionismo, tres a las divisiones de clases en la sociedad israelí y dos al papel de dicho Estado en el Medio Oriente y América Latina.

No es de extrañar que sólo una aborde la temática religiosa, en consonancia con el silencio casi total observado por el status confesional del país en esos años.

En los '90, los trabajos ascienden a un total de dieciocho, más del doble que en la década precedente. Once de grado, cuatro de maestría y tres de doctorado, elaboradas mayormente a partir de 1994.

Los factores desencadenantes de este incremento, para las de pensamiento político, serán el fin de la Guerra Fría y la desintegración de la URSS, la invasión de Kuwait y la Guerra del Golfo, los acuerdos de Oslo I y II, de Sharm el Sheij y Wye Plantation, la instauración de la autonomía administrativa en Gaza y la elección de Arafat, el asesinato de Rabin, la operación "Uvas de la Ira", las Conferencias de Paz de Madrid y MENA en Qatar y el diferendo en torno al status de Jerusalén.

De estas tesis, dos corresponden a estudiantes palestinos y reflejan el fenómeno de la Intifada y el Gobierno de Unidad Nacional en los territorios árabes. Igual número inicia una tendencia, que en la década siguiente se consolidará, al estudio del comportamiento de dos comunidades judías, una en Israel (rusa) y otra perteneciente a la Diáspora (norteamericana), tomando como punto de partida la influencia que se supone ambas ejercen en sus respectivas áreas de asentamiento. Las tres restantes analizan diversos aspectos del sionismo, el gobierno israelí y el conflicto sobre Jerusalén.

explicitan su origen. Los de Europa, Asia y África, al estudiar la Segunda Guerra Mundial, privilegian el análisis de la política imperialista enfatizando los cambios ocurridos en las metrópolis tras el fin de las mismas y la posterior lucha de liberación de los pueblos afroasiáticos, concediendo un espacio lectivo relevante al internacionalismo que rige la política del Partido y el Estado cubano.

Cuadernos Judaicos ISSN: 0718-8749 
La motivación fundamental, para las cuatro que abarcan temas de religión, en su mayoría referidas al pensamiento judío de la antigüedad y el europeo actual, será la posibilidad de adecuación a la realidad cubana actual de los presupuestos y el accionar de los profetas del siglo VIII, en relación con palabras claves como juicio, poder y esperanza.

Es significativo que en 1995, por primera vez desde los cincuenta, aparezcan cuatro estudios sobre Cuba y su comunidad hebrea.

La discreta alza, en este periodo, de tesis de índole religiosa y la irrupción de las de judaísmo local responderán, esencialmente, a cuatro estímulos: el retorno de teólogos protestantes formados en Alemania y expuestos al pensamiento de Buber, Rosenzweig, Arendt y Levinas, la creación del Instituto Superior de Ciencias de la Religión (ISECRE), la reorganización de la comunidad judía tras su extenso proceso de hibernación y el interés que despertaron en los estudiantes y profesores de la Universidad las publicaciones y conferencias ya mencionadas.

De las cuatro tesis sobre Cuba, elaboradas entre 1995 y 1998, dos narrarán la vida comunitaria en el país y otras dos se concentrarán en el destaque y rehabilitación del patrimonio arquitectónico judío, coincidentes con la visibilidad que sus sinagogas adquieren como espacio público a partir de su "renacer." 13

En los 2000 se alcanza el récord de cuarenta y nueve tesis: treinta y dos de grado, catorce de maestría y tres de doctorado. ${ }^{14}$

\footnotetext{
${ }^{13}$ Llama la atención que las dos tesis, una de maestría en Arquitectura y otra de grado en Historia del Arte producidas por miembros de la comunidad, hayan sido realizadas en el momento que los judíos no sobrepasaban los 1000 afiliados en la isla, y que ambas correspondieran a mujeres de origen sefaradí, a pesar de no ser éstas numéricamente la mayoría.

${ }^{14}$ El paso a un estadio superior en el nivel académico de los trabajos refleja la continuidad y profundización de ciertos temas previamente desarrollados en las de grado y maestría. Si desglosamos el total de las tesis producidas de 1986 al 2014 tendremos cincuenta y cuatro de grado, dieciocho de maestría y seis de doctorado.
} 
Significativamente, en esta década, los centros religiosos pasan a ocupar el primer lugar con veinte y seis tesis. Fenómeno que podríamos catalogar como una de las resultantes de nuestro "periodo especial" que atrajo, a la comunidad judía y a los templos de otras denominaciones religiosas, a individuos que habían estado apartados de las mismas y a personas no-practicantes que buscaban respuestas y compensación al vacío ideológico que, a partir de los 90, se produjo vis a vis la sociedad cubana.

Dieciocho serán estudios políticos, estructurados sobre dos grandes ejes temáticos que responderán por el $50 \%$ de la producción de tesis de este periodo: primero, el de las posiciones norteamericanas en el área y el impacto del lobby pro-israelí en la política exterior de los Estados Unidos hacia Irán y los palestinos y, segundo, el concerniente a la repercusión de la alyah de judíos rusos a Israel, temas ambos ya prefigurados en la década anterior.

Seis tesis se centrarán de nuevo en aspectos generales de la vida judía en Cuba. Dos analizarán el devenir histórico de sus diferentes asentamientos y, otras dos, profundizarán el patrimonio arquitectónico sinagogal, incorporando en esta ocasión el estudio de sus cementerios.

Por primera vez un trabajo abordará el antisemitismo europeo como fenómeno histórico mundial, tema que -aunque ajeno a nuestra realidad- fuera el principal causante de la inmigración judía a la isla, en tanto que otro destacará el rol de individualidades dentro de la comunidad. ${ }^{15}$

\section{Análisis por periodos}

Nos parece de utilidad para el análisis de los dos periodos en que hemos dividido este trabajo, tomar en consideración cuáles hechos incidieron de manera ostensible en el

\footnotetext{
15 Tesis sobre Abraham Marcus Matterin, hombre-puente desde 1950 entre la cultura hebrea y la sociedad cubana.
} 
pensamiento académico y cuáles motivaron las zonas de silencio que se aprecian en años como 1986, 1993, 1995-1997, 2000 y 2002.

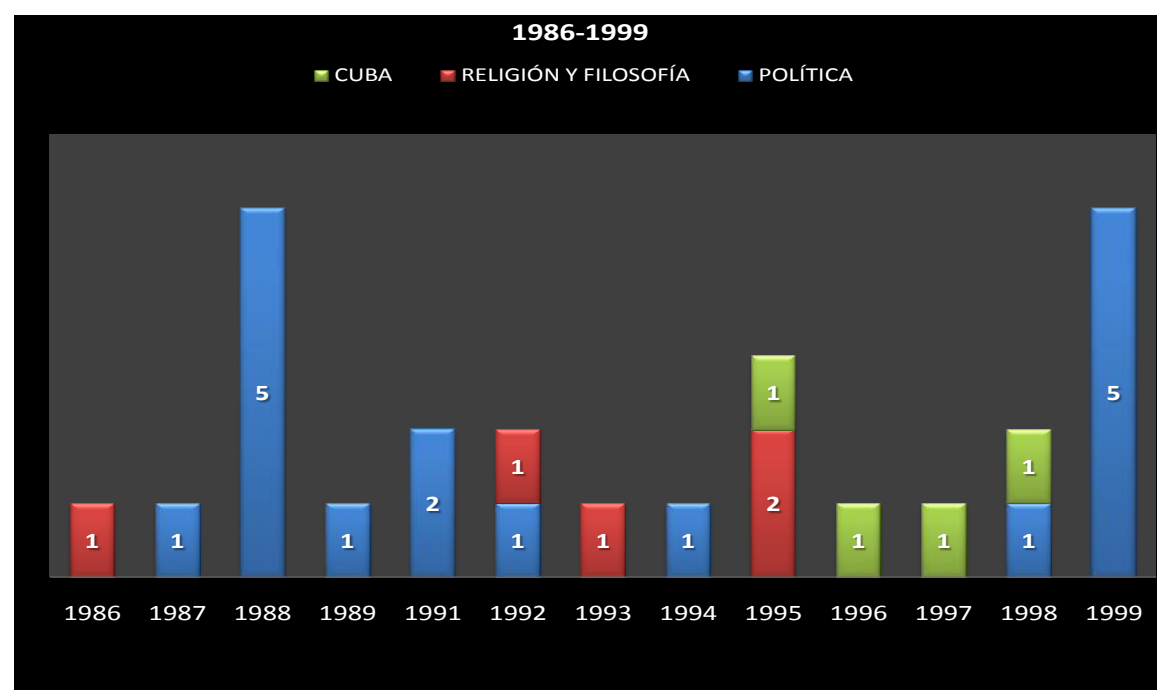

Tres eventos, de 1986 a 1999, podrían pensarse como definitorios para el diseño de la política exterior del país en relación con el área y para la investigativa como sustento de la misma:

- El impacto de los binomios Israel-USA y Cuba-URSS en cada una de las facetas de la vida socio-política y cultural cubana.

- La tradicional alianza que la isla estableciera desde 1947 con el mundo árabe, en su eterno diferendo con los Estados Unidos, potenciada por el más reciente apoyo a la causa palestina en tanto movimiento de liberación nacional.

- La agudización del desgaste de la imagen de Israel, iniciado tras la Guerra de los Seis Días y la del Kippur, por su alianza con Norteamérica y su participación en el comercio de armas con América Latina. 


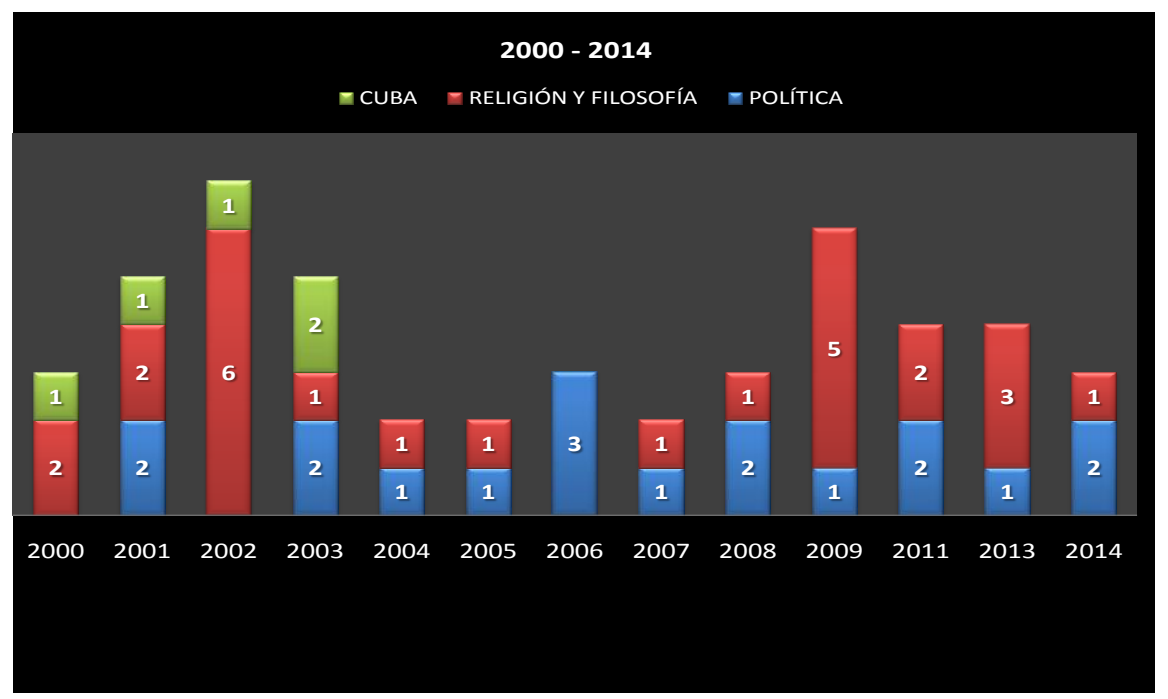

Para el comprendido entre el 2000 y el 2014 habría que añadir otros cuatro elementos, a saber:

- El retorno de las religiones, internamente "exiliadas" en el país, que incrementó la cantidad de personas incorporadas, con una nueva perspectiva, a la enseñanza y la práctica religiosa.

- La interminable Guerra Fría con Estados Unidos, aún sin solución definitiva, que convirtió en cuadrada la "armonía triangular"16 de Moshe Sharett, agudizando los procesos de deslegitimación del Estado sionista y modelando nuestras relaciones sociopolíticas y culturales con ambas áreas.

- El alza de los contactos políticos y las relaciones comerciales y de cooperación de la isla con el mundo islámico.

- Los investigadores y sus renovados intereses académicos.

16 A. Kacowicz, "Israel, las comunidades judias y A. Latina en un escenario internacional cambiante", Pertenencia y Alteridad, p. 251. Iberoamericana 2011. 
Del mismo modo, hay un grupo de acontecimientos que adicionalmente podría considerarse influyeron tanto en la relativa disminución de las tesis de contenido político y sus años de total ausencia, como en la vertiginosa alza de las de índole religiosa que traslucen estos gráficos.

El peso que las discrepancias surgidas en el seno de las distintas organizaciones palestinas tuvieron en el impugnamiento de la OLP y la sustitución de Arafat, en el estancamiento de los acuerdos para el autogobierno y la escalada de ataques y atentados suicidas en territorio israelí, en la renuncia de Barak y en la confección del informe Mitchell. Aspectos éstos que, conjugados con las desestabilizadoras consecuencias del periodo especial en Cuba y del 11 de septiembre en Estados Unidos, determinaron por una parte compases de espera que permitieran la inclusión de nuevas variables en el análisis de la región y, por otra, un lógico desplazamiento hacia comportamientos cotidianos más perentorios, dada la crisis económica interna por la que atravesaba el país, y una lógica tendencia al refugio compensatorio en las religiones provocada por las incertidumbres que a nivel individual dejaba el derrumbe, real o aparente, de la utopía socialista.

\section{Facultades y temas de investigación}

Los distintos centros de investigación presentan características bien delimitadas en la selección de los temas y en los enfoques que les imprimen. 


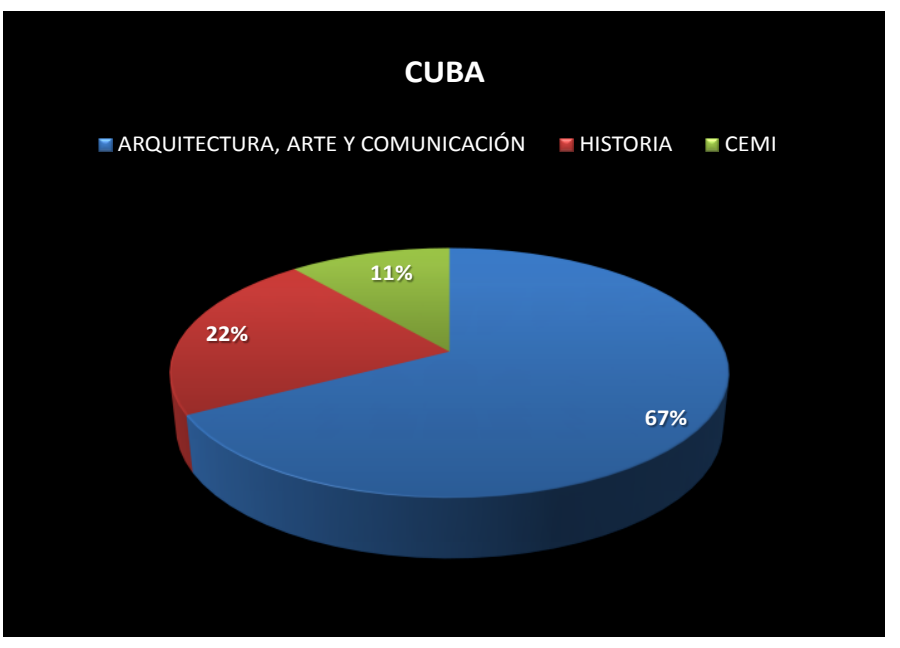

Las facultades de Arquitectura, Comunicación y Arte acaparan el 67\% del total de las tesis sobre $C u b a$, destacándose por su análisis del patrimonio material e intelectual judío (sinagogas, cementerios, áreas de la ciudad que habitaron y personalidades) exentas de matices políticos.

Los trabajos de la carrera de Historia (22\%), que versan sobre la vida judía en la isla en el periodo pre-revolucionario, y los del Centro de Estudios de Migraciones Internacionales (11\%) destacan el papel abierto de la sociedad en la recepción de esta minoría, mientras que las que se aproximan a la coyuntura actual resaltan la convivencia sin conflicto de dicha Comunidad con las estructuras de Partido y Gobierno.

Es evidente que en las diferentes aproximaciones al tema Cuba la formación diaspórica, en tanto grupo asentado en la isla, se beneficia de una mirada que escapa al excesivo ideologicismo con que se afronta el tema Israel. 


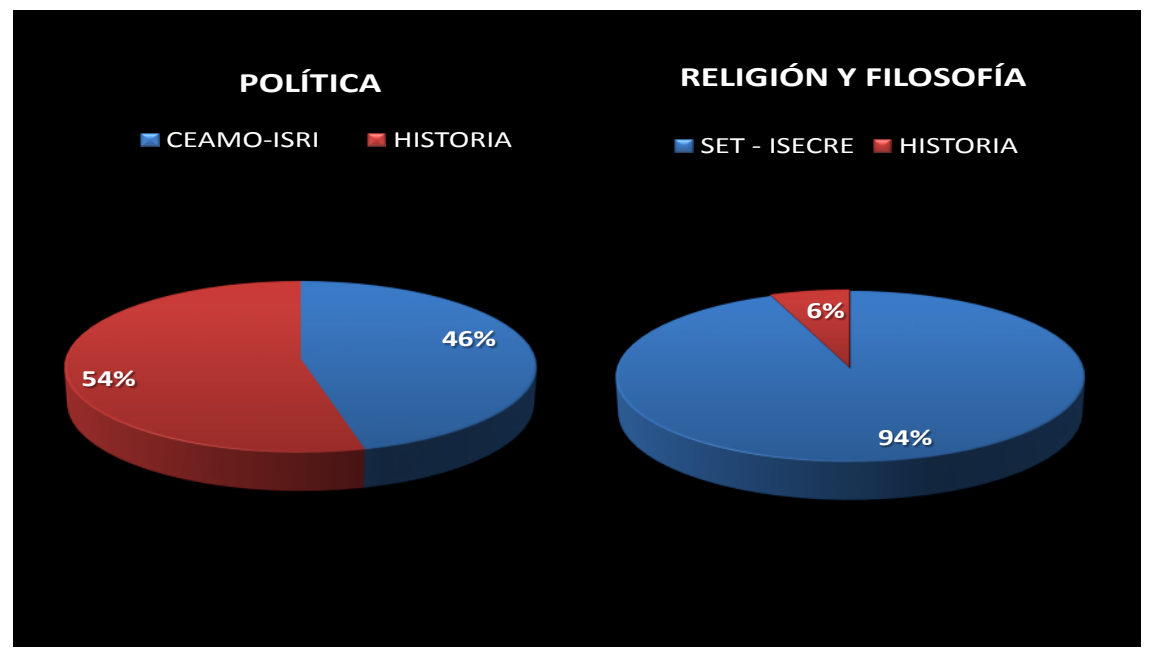

En las de temática Política la facultad de Historia produjo ella sola el $46 \%$ de la totalidad, mientras que en conjunto las de los tres centros especializados, Centro de Estudios de África y Medio Oriente (CEAMO), Instituto Superior de Relaciones Internacionales (ISRI) y, en menor medida, el Centro de Estudios de Migraciones Internacionales (CEMI) representan el $54 \%$ restante.

Estas tesis abordan las estrategias adoptadas por Estados Unidos e Israel, en un área que incluye desde Iraq, Libia, Líbano hasta Kosovo, haciendo especial énfasis en el conflicto palestino con una valencia crítica y controversial de la realidad sionista, y con consideraciones políticas y narrativas socioculturales que, en ocasiones, desbordan la estricta percepción histórica.

El ISECRE y el SET responderán por el 94\% de las tesis sobre Religión, exhibiendo un espectro mucho más variado, con currículos que estudian a profundidad dicha temática. ${ }^{17}$

\footnotetext{
${ }^{17}$ Estos trabajos denotan, por lo general, admiración por los filósofos y pensadores judíos, analizan aspectos del Antiguo Testamento, principalmente de los Profetas, o son proclives a la aproximación del misticismo cabalístico. Los contenidos curriculares de estos centros incluyen historia de Cuba y del Mundo Antiguo, en especial la de Israel, dedicando un semestre a la religión en Cuba, otro a los Textos Sagrados, dos de Introducción al Antiguo Testamento, y dos de Teología Bíblica y Exégesis del Antiguo Testamento, impartiendo también Hebreo Bíblico y Hebreo Avanzado.

Hay coincidencia en los criterios expuestos en el panel de LAJSA para los casos de Perú y Cuba con los de Senkman (El judaísmo en la cultura, en Bokser et al. pp.692-94) en cuanto a la 
Las dos realizadas por la facultad de Historia pertenecen a una misma estudiante/maestrante, y analizan el pensamiento judío en la antigüedad y su proyección posterior en Europa.

Resulta de interés destacar que los trabajos de los centros religiosos trascienden la aproximación exegética y teológica al tema para insertarse en un espacio de la Cuba actual. A través de la vinculación de una posible vigencia del profetismo, el mesianismo, el sufrimiento esperanzador de Job, la relectura del exilio babilónico como el lugar donde se reconstruye la esperanza, o la visión teológico-política del pensamiento judío europeo más actual de figuras como Rosenzweig o Arendt, la mujer en el Pentateuco como protagonista de la historia de salvación, el rabinato femenino en los siglos XX y XXI o una nueva y osada mirada de género en un recuento de "hombres al desnudo" desde David a Onán, estas tesis sin dudas reformulan códigos inusuales de entendimiento de la realidad socio-política de la isla.

\section{Espacios de diálogo}

Es posible afirmar que el diálogo nacional establecido entre la comunidad judía y la sociedad, académica o no, ha tenido y tiene un nivel de incidencia atendible, a pesar del exiguo tamaño de dicha comunidad y del reducidísimo sector dentro de la Academia que la estudia. Ejemplos de esta interacción:

Los trabajos presentados en las Conferencias Internacionales de LAJSA en el continente americano, en el Congreso Mundial de Estudios Judaicos en Jerusalem y en eventos nacionales desde 1995 hasta la actualidad, que fueron difundidos dentro de la comunidad, motivaron una mirada autorreferencial que produjo textos sobre la vida judía en el país, las sinagogas y cementerios que han sido, parcial o integralmente, publicados.

importancia de indagar cómo la legitimación de los estudios judaicos logró mayor coherencia en las universidades cristianas de México y Brasil que en las nacionales laicas. 
El evento por el Centenario de la República, organizado por la Universidad de La Habana en el 2002, tuvo gran impacto en la Academia al ser la primera vez que se analizaba, en una reunión de esa envergadura, la inmigración judía como parte del etnos cubano, lo que podría interpretarse como un intento de redefinir la identidad nacional en términos culturales más pluralistas, trascendiendo la tradicional dicotomía blanco/negro que ha prevalecido en nuestros estudios. ${ }^{18} \mathrm{El}$ interés suscitado por esta presentación determinó la inclusión del trabajo en la revista Debates Americanos y propició la realización, en el 2003, del plegable Presencia Hebrea en Cuba acometido por la Fundación Fernando Ortiz.

La publicación en el 2005 del libro La Isla Elegida, los judios en Cuba, incentivó a alumnos y profesores de la Universidad a investigar y preparar tesis sobre distintos aspectos relacionados con la vida judía en el país, su pensamiento filosófico y el antisemitismo, entre otros. También desbrozó el camino para la edición del libro de Donde son los cubanos como colofón del panel presentado en el citado evento de la República, donde se analizan de manera comparativa cuatro inmigraciones minoritarias en la isla: la judía, la angloantillana, la china y la haitiana.

Estos libros sobre la historia de los hebreos cubanos, que llegaron a las editoriales nacionales y participaron en la Feria Internacional del Libro de La Habana y en las del interior, fueron muy bien recepcionados e incluso reimpresos, acercando de manera ostensible la comunidad judía a la sociedad cubana. Siguiendo esta línea, se aprecia como las provincias con comunidad y cementerio se legitiman en la esfera pública interactuando dinámicamente con las estructuras de Partido y Gobierno en la región, y divulgando su historia a través de exposiciones y conferencias de marcado carácter ecuménico.

\footnotetext{
${ }^{18}$ Semejante accionar también se observa en el supuestamente homogenizador proceso identitario mexicano de los ochenta (Senkman, ibidem, pp. 687-89) 


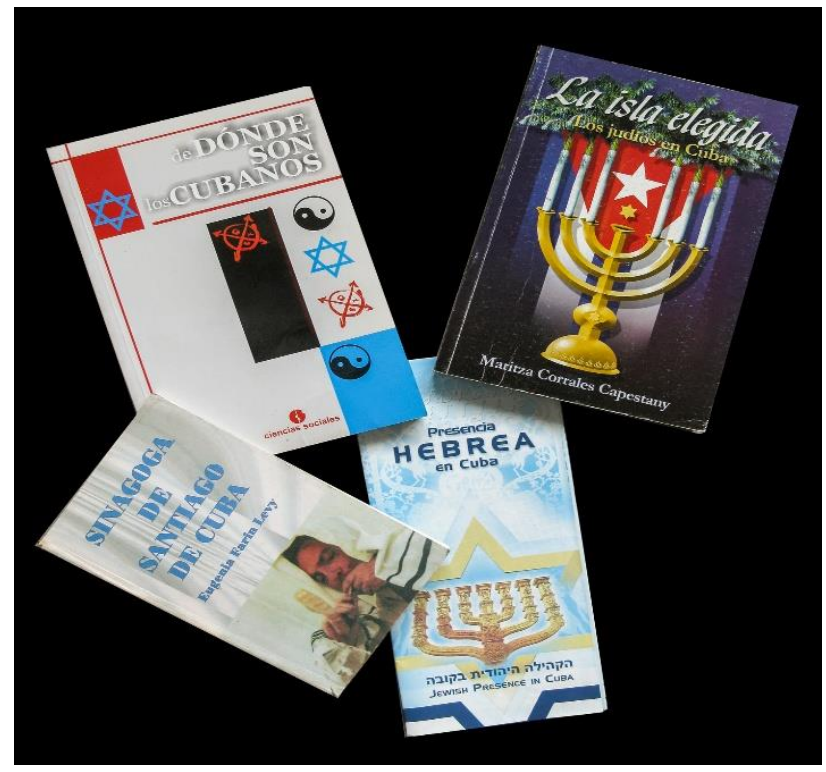

Como fenómeno concurrente, y con una visión de lo judío exógeno no tan legitimadora, podrían citarse los libros y folletos publicados por la Embajada de la Organización para la Liberación de Palestina en la década de los ochenta, algunos de la Editora Política, la colección de documentos sobre la injerencia sionista y las revistas de África y Medio Oriente del CEAMO.

Jornadas internacionales como la de la "Cultura Sefaradí", celebrada en el 2009, y otros eventos patrocinados por la comunidad, insertaron textos en importantes publicaciones nacionales (La Siempreviva, Opus Habana), y promovieron documentales, programas radiales y televisivos sobre la impronta de esta minoría en la isla.

La inauguración en el Centro Hebreo Sefaradí de una exposición permanente, y única en el país, sobre el relevante papel que la nación cubana tuviera en la salvaguarda y rescate de judíos durante el Holocausto, permitió llevar esta realidad a nuestras escuelas instalando la memoria de la Shoá y enriqueciendo el escaso conocimiento que de ella poseen las nuevas generaciones, tan alejadas de ese momento histórico.

La visibilidad adquirida por este diálogo, desde la Academia, la sociedad y el espacio comunitario, ha hecho que destacados escritores cubanos, entre ellos varios Premios 
Nacionales de Literatura, incorporen nuestra temática a sus obras. ${ }^{19}$ Del mismo modo, ha propiciado que instituciones culturales nacionales homenajeen, de manera rotunda, a destacados intelectuales asumiendo su origen judío, reconociendo las huellas y la importante contribución que han legado a nuestra cultura. ${ }^{20}$
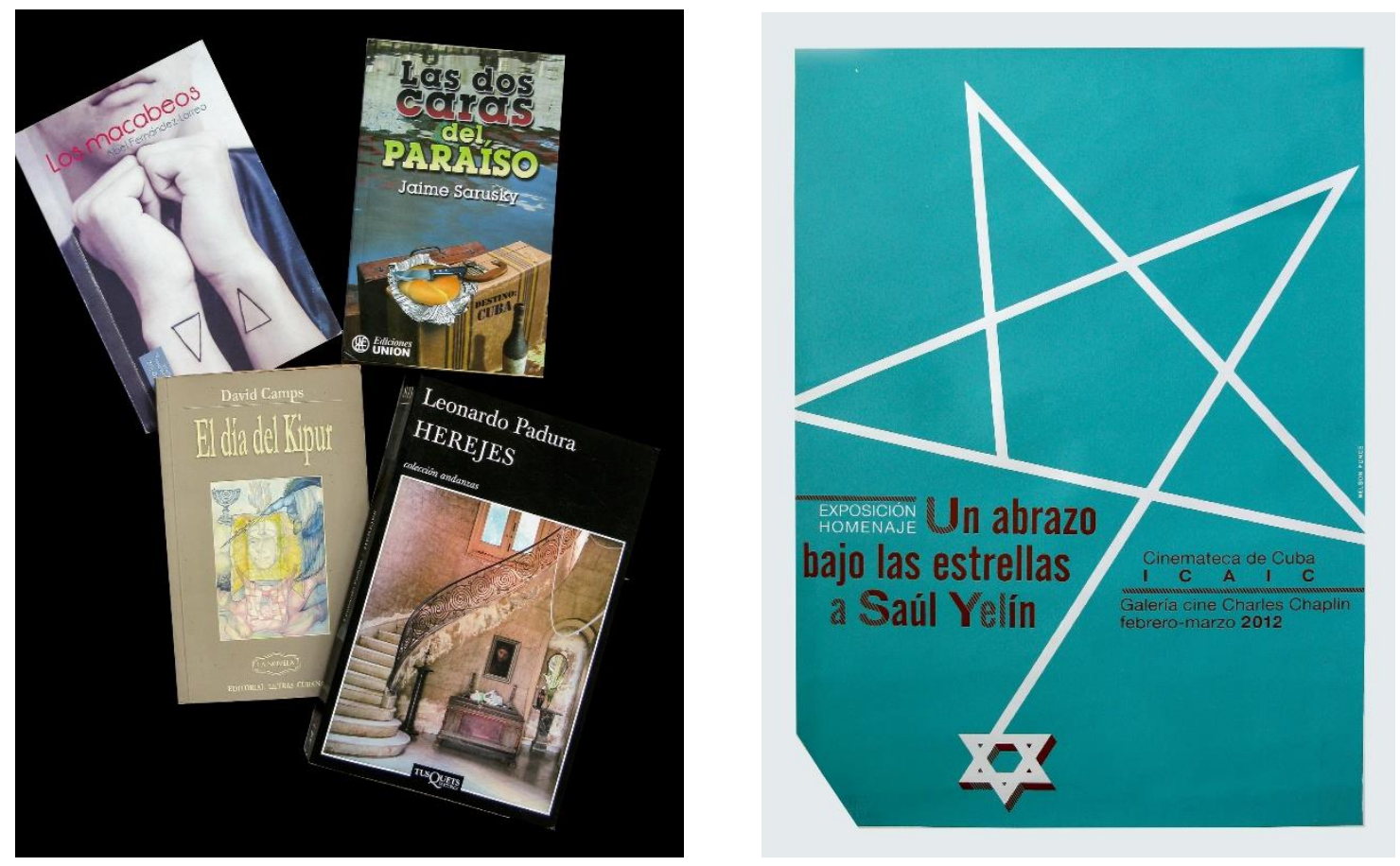

\section{Consideraciones finales}

A pesar de la ausencia de articulación de nuestro tema dentro un departamento específico, la persistencia de unos pocos en investigar, divulgar e incentivar un objeto de estudio escasamente conocido en nuestro medio académico ha brindado sus frutos.

${ }^{19}$ Entre ellos, Leonardo Padura con su libro Herejes, Reynaldo González con Al cielo sometido, Jaime Sarusky con el tardío pero sentido acercamiento al tema en La otra cara del paraíso, David Camps, La noche del Kippur, Víctor Fowler, El maquinista de Auschwitz, Samuel Feijoó con BethEl y, recientemente, Abel Fernández Larrea con Los Macabeos.

${ }^{20}$ Por ejemplo, a Saúl Yelín, fundador del cine cubano post 1959, y al premio Nacional de Literatura y Periodismo Cultural, Jaime Sarusky. 
Si bien el campo de dichos estudios en Cuba analiza una comunidad que para el país constituye una "minoría de minorías", otra es la realidad en el plano internacional donde existe un circuito académico ampliamente reconocido, tanto por la calidad de sus investigaciones como por la prolijidad de sus eventos. Este reconocimiento ha contribuido también a que profesores y alumnos, revisiten las posibilidades que el tema ofrece y comiencen a alejarse en lo posible del tradicional análisis sociopolítico, acometiendo investigaciones que incorporen otras aristas y miradas del judaísmo.

Si añadimos a esta tendencia, que ya se va materializando, el posible impacto del $17 \mathrm{D}$ para las relaciones entre Cuba e Israel, la fuerza descontrolada de los movimientos islámicos fundamentalistas, un interés renovado hacia la judería norteamericana a partir del conocimiento de las claves políticas y de influencia mediática que le son intrínsecas, junto a la probable formación de una plataforma más amplia a estructurarse por las diferentes denominaciones religiosas en los próximos años en el país, podría esperarse no sólo un fuerte incremento de los estudios judaicos, en sus variantes religiosa, histórica, filosófica y política, sino también acercamientos disciplinarios y analíticos con una aproximación más matizada y plural de los temas que conciernen al área Medio Oriental dentro de la Academia.

También prevemos que a lo interno del mundo comunitario se verificará, tras el largo periodo de hibernación y sensibilización experimentado, un retomar de aquella olvidada conciencia de su memoria histórica que, tan sentida y eficientemente, desarrollaran las generaciones precedentes en las décadas de los treinta, cuarenta y cincuenta.

Es importante destacar la coincidencia de criterios, observada entre los colegas participantes en el panel de LAJSA sobre los estudios judíos en Latinoamérica, de que debemos arribar a un estadio superior en lo relativo al rigor metodológico y teórico y, también, a la superación de los límites en muchos casos estrechos de una narrativa estrictamente descriptiva y focalizada en los rasgos distintivos de cada una de estas 
comunidades en sus respectivos países, o de un análisis excesivamente politizado y unilateral de una realidad tan compleja y paradójica como la medioriental.

De igual modo concordamos con los señalamientos ${ }^{21}$ de que debería incentivarse el estudio del sefardismo ya que, a pesar de ser el material primigenio y fundacional de nuestras comunidades en el área, no exhibe igual peso que los trabajos dedicados al grupo asquenazí.

Sin dudas, se imponen abordajes que cuestionen los paradigmas históricos tradicionales y provoquen estudios más flexibles y abiertos a nuevas representaciones de lo judío, de su pertenencia y alteridad y de las variadas reconstrucciones de sus identidades plurales, en perpetua transformación y simbiosis con nuestras culturas y sociedades. Trabajos que superen el déficit interdisciplinario y las consabidas lógicas binarias, no sólo expandiendo el objeto de estudio con nuevas problemáticas sino, sobre todo, con miradas diferentes.

Por último, se precisan análisis que incluyan acercamientos a la rediasporizacion y transnacionalización de esta diáspora etno-nacional, a las convergencias y/o divergencias de sus procesos de asentamiento, inserción e integración/asimilación ${ }^{22}$ con las de los otros grupos migratorios en la isla, cotejando los contextos nacionales en sus diversos tiempos con aquellos del continente, a fin de poder aprehender en toda su dimensión y potencialidad este gran cruzamiento cultural que es el ajiaco cubano, la feijoada brasileña o las muy variadas mixturas que en nuestras tierras asume, desde siempre, lo real maravilloso Carpenteriano.

\footnotetext{
${ }^{21}$ Véase Monica Grin, Estudos Judeos, p.9.

${ }^{22}$ Boxer et al., (pp. 49-50). Los análisis comparativos de Jeffrey Lesser y Ranaan Rein para los casos de Brasil, Argentina, incluso el intento de Cuba con De donde son los cubanos son ejemplos de visiones más integrales de las posibilidades de estos estudios.
} 


\section{Bibliografía}

Bokser Liwerant, Judit et al. Pertenencia y alteridad. Judíos en /de América Latina: cuarenta años de cambio, Iberoamericana-Vervuert, 2001.

Grin, Monica. "Estudos Judeos no Brasil: em busca de uma nova agenda", NIEJ, Nucleo Interdisciplinar de Estudos Judaicos, revista digital de la Universidade Federal do Rio de Janeiro, Año 1, No. 1, 2009.

Ortiz, Fernando. "Los Factores humanos de la cubanidad", Revista Bimestre Cubana, 45, No. 2, marzo-abril de 1940.

Pérez, Mileidys. "La enseñanza de la historia de Cuba a nivel secundario desde el triunfo de la Revolución hasta 1988", tesis inédita, Universidad de La Habana, 2001.

Pérez de la Riva, Juan. "Los recursos humanos al comenzar el siglo: Inmigración, economía y nacionalidad 1899-1906", La República Neocolonial, Anuarios de Estudios Cubanos I (La Habana), 1975, pp. 11-44.

Universidad de La Habana, Facultad de Filosofía e Historia, Departamento de Historia, Programas de la carrera de Historia, La Habana.

\section{ANEXO}




\section{$\underline{\text { Libros, folletos y artículos sobre temática judía publicados en Cuba, 1986-2014 }}$}

Badía, Boris, "El neobarroco kozereano: un islote de singulares resonancias", La Siempreviva, No. 18, La Habana 2014.

Colectivo de autores, "Centenario de la Comunidad hebrea de Cuba, 1906-2006." Menorah, La Habana, agosto 2006.

Colectivo de autores, "Viaje al centro de Sarusky", Suplemento Literario de Revolución y Cultura, Edición especial, La Habana 2001.

Corrales, Maritza, "Comportamiento económico y espacial de los comercios e industrias judías de La Habana: 1902-1959." Encuentro y Alteridad. Vida y cultura judía en América Latina, Fondo de Cultura Económica, la Universidad Autónoma de México y la Universidad Hebrea de Jerusalén, 1999.

"Los judíos en Cuba republicana", Debates Americanos, No.12, enero-diciembre 2002, La Habana.

Presencia Hebrea en Cuba, Fundación Fernando Ortiz, 2003.

Fragmentos de un pasado. 60 Aniversario de la Logia B'Nai B'rith Maimónides de Cuba, La Habana 2003.

The Chosen Island: Jews in Cuba, Salcedo Press, Estados Unidos 2005.

"Continuidad", Opus Habana, Vol. IX, No.1, La Habana 2005.

La Isla Elegida. Los judíos en Cuba, Editorial Ciencias Sociales, La Habana 2007.

De dónde son los cubanos, Editorial Ciencias Sociales, 2005 y 2007.

Cuadernos Judaicos ISSN: 0718-8749 
"Revolution, Ethnicity and Religions in Cuba: Similarities, Differences, and Dichotomies in the case of the Jews", Identities in an Era of Globalization and Multiculturalism, Ediciones Brill, Holanda 2008.

"Convergencias y desencuentros entre árabes y judíos de Cuba", Árabes y Judíos en Iberoamérica, Fundación de las Tres Culturas (España) y Universidad de Tel Aviv 2008.

"Refugiados italianos de origen judío en Cuba: 1938-1946", Emigrazione e presenza italiana in Cuba, Circolo Culturale B.G. Duns Scoto, Italia 2008.

"De libertades y exilios: José Martí y los hebreos cubanos", Judaica Latinoamericana, AMILAT, Universidad Hebrea de Jerusalem 2009.

"Comunistas judíos: Contrapunteo cubano y contrahistoria de una comunidad, 1925-1953", Judaica Latinoamericana, AMILAT, Universidad Hebrea de Jerusalem 2009.

"Bruno Colombo: un hombre bueno que cruza fronteras, un sonador empedernido y culto", Cuadernos de Italianística cubana, Año XII, No.19, La Habana, mayo 2012.

Eli, Matilde, "En busca de las raíces", Cimientos, Año 3, No.5, La Habana 2002.

Farín, Eugenia, El judaísmo en Cuba, Colombia 2004.

Sinagoga de Santiago de Cuba, Comunidad Hebrea de Santiago de Cuba, Santiago 1999

García Verdecia, Manuel, "El animoso castor José Kozer", La Gaceta de Cuba, UNEAC, La Habana, septiembre-octubre 2013.

Hernández, Adriana, "Los judíos y la Modernidad", Universidad de La Habana, No.275, enero-junio 2013. 
Marrón, Eugenio, "José Kozer en estado de escritura y lectura, La Siempreviva, No.18, La Habana 2014.

Rigol, Isabel, El cementerio Macabeo de Guanabacoa", Revolución y Cultura No.4, La Habana 2001.

Sabater, Miguel, "Los judíos en Cuba", Palabra Nueva, Año XV, Nos. 155 y 156, Arquidiócesis de La Habana, septiembre y octubre 2006.

Sánchez Porro, Reynaldo, "Tradición y modernidad: Los judíos en Cuba", Revista de África y Medio Oriente, 10 (1-2), La Habana 1998.

Sosa, Adriana, "Judeolenguas en Cuba: un caso de lenguas en contacto, Universidad de La Habana, No.275, enero-junio 2013. 